\title{
Note for the Second Part of Special Issue: Clinical Social Work Education in its Digital Format
}

\author{
Qingwen $\mathrm{Xu}^{1} \cdot$ Charles Figley ${ }^{2,3}$
}

Accepted: 21 January 2022 / Published online: 7 February 2022

(c) The Author(s), under exclusive licence to Springer Science+Business Media, LLC, part of Springer Nature 2022

As we complete the second part of Special Issue, the world has experienced the Delta wave and now the surge of Omicron. The demand for remote work persists in many workplaces; school districts and universities, after a semester long in-person teaching, again switch to online learning temporarily. The prolonged Covid pandemic has been testing many aspects of social work education and professional practice in today's digital society.

No other mental health profession emphasizes the social environment more than social work. The digitalized social environment has defined social work fields of practice, and affected how the profession should train students. In the last decade, social work education has responded to and welcomed the use of digital technology, exemplified by the growing online social work programs in general (CSWE, 2020), and the adoption of virtual reality and computer simulation in teaching clinical practice in particular (Huttar $\&$ BrintzenhofeSzoc, 2020). However, the Covid-19 pandemic presents unique challenges that social work education has not been fully prepared for-remote field placement and supervision, students' perception and skills in the use of technology, and teaching and learning in a shared trauma environment. Such challenges call for educators' immediate responses.

In this collection, we have social work students, researchers, practitioners and educators who were able to document their responses, experiences, reflections and later conceptualizations from a professional perspective. Innovations in field education, and new pedagogical approaches to teaching clinical practice during the pandemic were reported; these

Qingwen Xu

qingwen.xu@nyu.edu

1 New York University Silver School of Social Work, New York, NY, USA

2 Distinguished Chair in Disaster Mental Health, Tulane University, New Orleans, USA

3 Traumatology Institute, New Orleans, USA educational models are promising and can be sustained in the era of e-mental health. Mitchell and colleagues developed a prototype for remote/virtual field placement; Dempsey and colleagues proposed and tested the use of reflections-on-action in field education. Two articles authored by Gates, Wohlsifer and colleagues discussed their adaptations to teaching clinical practice courses; while each adopted different strategies, both emphasized the importance of self-compassion and group cohesion among students and instructors.

This special issue also includes four articles that describe social work students' experiences in the context of public health disaster and digital learning. Among these articles, students reported varied yet unified pandemic-related stress and shared trauma experiences, but nonetheless demonstrated capacities of coping and meaning making for both personal and professional growth. MSW students in Bloomberg, Tosone, and colleagues' article reflected on various shared traumatic experiences and complexities of life ushered in by the pandemic; undergraduate social work students in a study conducted by Apgar and colleagues adopted the coping skills they learned for their clients; doctoral students in Berger and colleagues' work demonstrated a developmental process of coping. And Earle and colleagues surveyed students' perception of e-therapy, comparing the results with a similar study published 20 years ago; results affirmed the increased interest in e-therapy, concluding with the need for inclusion of e-mental health in professional training.

Effective clinical social work education rests on the interactions between class teaching and field learning; it values student participation, and a collaborative process to co-create a teaching-learning environment wherein students, instructors and field supervisors would critically analyze and respectfully value diverse human identities and social relationships. These articles deepen our understanding of the ways students learn and grow; they also contribute to our educational practice and enhancement of the teaching-learning environment. 
As the world hopefully moves toward the end of Covid-19 pandemic in 2022, the social work profession will likely undergo structural changes, and such changes may accelerate due to not only technological advances but also changed group behaviors, social expectations and professional norms. The incorporation of technology in clinical practice, and the larger mental health care and social service systems, will bring profound changes in social work education. In addition to digital formats, we are reminded that social work teaching, learning and performing are deeply participatory and committed to justice and social change. With these changes, future social workers can better position themselves in every society in which they live, work and strive.

\section{References}

Council on Social Work Education (CSWE). (2020) 2019 statistics on social work education in the United States. https://www.cswe. org/Research-Statistics/Research-Briefs-and-Publications/2019Annual-Statistics-on-Social-Work-Education

Huttar, C. M., \& BrintzenhofeSzoc, K. (2020). Virtual reality and computer simulation in social work education: A systematic review. Journal of Social Work Education, 56(1), 131-141.

Publisher's Note Springer Nature remains neutral with regard to jurisdictional claims in published maps and institutional affiliations. 